\title{
LATERAL STABILITY OF A MULTI-STORY BUILDING UNDER BLAST LOAD
}

\author{
Priyanka $\mathbf{A}^{\mathbf{1}}$, Rajeeva $S \mathrm{~V}^{\mathbf{2}}$ \\ ${ }^{I}$ PG student, Department of Civil Engineering, K.S School of Engineering and Management, Bangalore, India \\ priyathammaiah17@gmail.com \\ ${ }^{2}$ Professor, Department of Civil Engineering, K.S School of Engineering and Management, Bangalore, India \\ svraj06@gmail.com
}

\begin{abstract}
This paper presents the lateral stability of a multi-story building subjected to blast load. The basics of blast threats and the of blast wave interaction with buildings are studied here. It is about investigating the lateral stability of a structure modeled using SAP2000. Building is of 6 story is exposed to $100 \mathrm{~kg}, 200 \mathrm{~kg}, 300 \mathrm{~kg}, 400 \mathrm{~kg}$ and $500 \mathrm{~kg}$ TNT with $6 \mathrm{~m}$ stand-off distance. The blast loads are considered using the approaches defined in section 5 of TM5-1300 (UFC 3-340-02) and for the analysis of the dynamic load of the blast, a nonlinear modal analysis is used. The total drift and the inter-story drift are the primary parameters that determine the performance of the structure.
\end{abstract}

Keywords: Blast Load; Time History Analysis; Standoff Distance; TNT; Positive Phase

$* * *$

\section{INTRODUCTION}

As many researchers, author and many people defines an explosion is an occurrence of sudden release of huge scale of energy and explosive resources may be condensed, solid or liquid which regulates the speed of the reaction. In recent years, exceptional concern has been given to quick-tempered loads on breakthrough structures, such as high rise buildings in urbanite cities, public buildings, delegations, economic institutions and other buildings of national inheritance. Explosions occur as a result of accidental and intended incidents. The intentional explosions include unprepared explosive devices, weapon systems and demolition threats. Accidental explosion can be caused by the burning of flammable solutions and gas mass due to fire or damage to hassled containers. Explosives continue to be the strongest weapon of fanatic organizations, for they are very critical, easy to produce, achieve and move from one place to another. The explosion of bombs in and around buildings can cause terrible impacts on the structural dependability of the structure, such as destruction to the internal and external structural members such as beams, columns slabs and collapse of walls. Loss of social life can result from the collapse of the structure, effect of direct blast, fragments impact, fire and smoke. Many cities have become target of bomb explosion attacks in the last decades. Some terrorist groups have targeted buildings around the world. The cases of those attacks proved the exposure of buildings to explosion

\section{EFFECT OF BLAST LOAD ON STRUCTURES}

Explosions can be characterized on the source of their nature as physical, nuclear or chemical actions. In physical explosions, heat energy may be released from the terrible failure of a cylinder of compressed gas, volcanic discharges or even mixing of two liquids at altered temperatures. Explosive materials can be categorized according to their physical state as solids, liquids or gases. [1], [2] and [3].

From a reflection of an external blast wave, façade of the structure experiences peak over pressure. Once the primary blast wave are circulates from the reflected surface of the building, the peak overpressure decays to zero or to normal ambient pressure. A releasing effect of blast overpressure is experienced on the front face. The overpressure on the front surface of the structure continues to decrease until the pressure is equalized with the pressure of the surrounding air.[2], [4] and [5].

The paper, nonlinear analysis of shear walls is presented. The example building subjected to the explosion of $1000 \mathrm{~kg}$ of TNT at a stand-off distance $30 \mathrm{~m}$ from the building. Walls of $9 \mathrm{~m}, 21 \mathrm{~m}$ and $60 \mathrm{~m}$ high, with $12 \mathrm{~m}$ width are analyzed and the thickness of walls is $0.25 \mathrm{~m}$. At the primary stage, the wall was designed to withstand the wind load and vertical gravity load in direct zone of stress-strain curve diagram. Reinforced concrete wall model was generated in 3 dimension element SOLID65. Shear walls with and without openings are considered in the study and they were analyzed with the major influence of blast [6].

This paper statistically inspects the tilt response of multistory buildings due to the progressive collapse of the neighboring underground structure subjected to internal blast loading where percentage of confinement is considered. The 3d software LS-DYNA is employed to establish a threedimensional combined model serene of the underground construction, the soil nearby and the next to above-ground level. By relating tilt response of the structure above-ground level of different types due to the effect of progressive 
collapse of underground structure under its confined blast loading, it is initiated that the tilt response of the structure above-ground level of different categories is correlated to the foundation part of the structure [7].

\section{Blast load Characteristics}

At any locality away from the explosion, the pressure disturbance has the configuration shown in Fig 1. The blast wave façade reaches at a given surrounding at time ta, and after the rise to the peak value, Pso the incident pressure decreases to the reference ambient value. The time taken is known as the positive phase duration. This is tracked by a negative time period with an extent of load to that is generally much longer than the positive time period. It is categorized as a negative pressure time below normal or zero pressure having peak magnitude of Ps. It occurs along disorder of the particle flow. The negative phase has less importance in a design than the positive phase, and its amplitude Ps must be less than ambient reference pressure Po. The instance impulse density related with the blast wave is the combined area below the pressure v/s time condition.

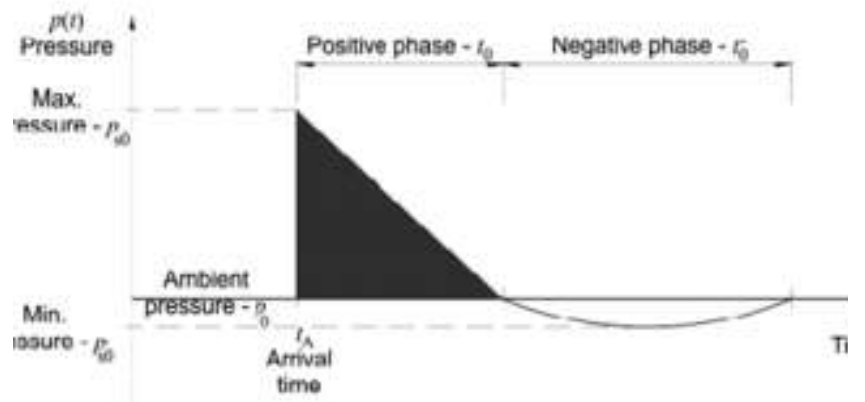

Fig 1: Typical pressure-time history

\section{STRUCTURE AND ITS PROPERTIES}

Six story reinforced concrete framed structure is considered with 2 spans of $6 \mathrm{~m}$ and 4 bays ( 2 bays of $7 \mathrm{~m}$ at the extremity and 2 bays of $5 \mathrm{~m}$ in the middle). The first story height is $4 \mathrm{~m}$ and all the other levels are $3 \mathrm{~m}$ high each. Dimensions of the columns are $600 \mathrm{~mm} \times 600 \mathrm{~mm}$, the reinforcement is $4 \varnothing 25 \mathrm{~mm}$ on a side. Dimensions of the perimeter beams are $250 \mathrm{~mm} \times 550 \mathrm{~mm}$ and $300 \mathrm{~mm} \times 700 \mathrm{~mm}$ for the central beams. Thickness of the slab is $150 \mathrm{~mm}$. The concrete compressive strength at 28 days is $30 \mathrm{MPa}$ with elastic modulus of $32.5 \mathrm{GPa}$. The yield strength of reinforcement is $300 \mathrm{MPa}$ with elastic modulus of $210 \mathrm{GPa}$.

With the above details model is generated in FEM software SAP 2000. Six story building is modeled as framed structure. The beams and columns are generated as framed sections and the slab is modeled as shell elements. The fixed support condition is applied for columns. Non-linear modal analysis is carried over in present study. Time history function is main aspect to investigate the lateral stability of a structure as time is a major domain in blast. A very small time period is essential to get stable results. The details are taken from literature [8]. The typical floor plan is shown in Figure 2.

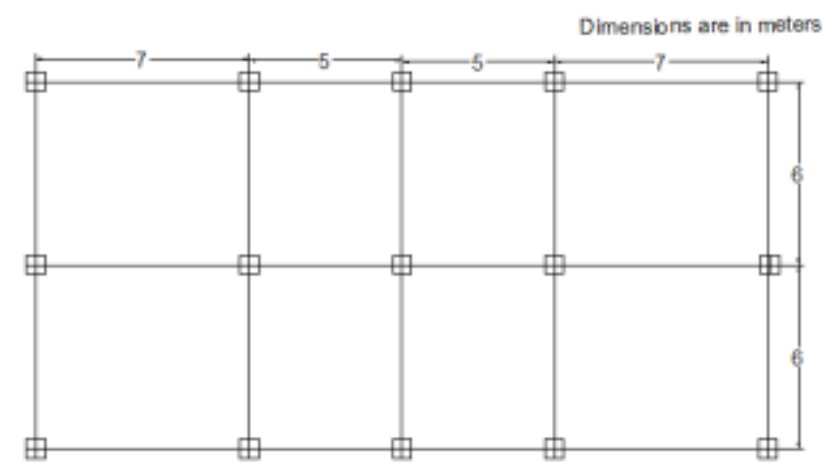

Fig 2. Typical floor plan

\section{Blast Load Determination}

The procedures outlined in section 5 of TM5 -1300 (1990): Structures to resist the effects of accidental explosions, developed by the US Department of Defense are used to evaluate the maximum blast load that is applied to the structural members of the building. The blast load parameters are generated using different charge weights of $100 \mathrm{~kg}, 200 \mathrm{~kg}, 300 \mathrm{~kg}, 400 \mathrm{~kg}$ and $500 \mathrm{~kg}$ TNT placed at $6 \mathrm{~m}$ standoff distance. The blast loads are distributed on all the structural elements on the front face of the building. Dynamic parameters for the blast load such as the shock front velocity, time of arrival, impulse and duration are calculated.

The blast is always reflects as pressure. It can be converted to blast load which is applied as a point load on each node in the front face of the targeted multi story building by using the time history function. For example, the pressure due to blast load is multiplied by surface area of the designed frame which has a column of height $4 \mathrm{~m}$ in ground level, span length of the bay/beam is $7 \mathrm{~m}(4 \mathrm{mx} 7 \mathrm{~m})$ and divided by number of nodes in a frame which has 4 nodes and we will get the value of point load on each node. Table I gives the variation of blast pressure in bay 1, along the height of the structure for the charge weight $100 \mathrm{~kg}$ TNT at a standoff distance $6 \mathrm{~m}$

$\operatorname{Pr}=228$ psi which is equal to $228 \times 6.89=1571 \mathrm{kN} / \mathrm{m}^{2}$ Load on each node $=\{1571 \times(7 \times 4)\} / 4=10997 \mathrm{KN}$

TABLE I. variation of blast pressure in bay 1, along the height of the structure for the charge weight $100 \mathrm{~kg}$ TNT at a standoff distance $6 \mathrm{~m}$

\begin{tabular}{|c|c|c|c|c|c|c|}
\hline Bay 1 & \multirow{2}{*}{$\begin{array}{c}\text { R } \\
(\mathbf{f t})\end{array}$} & \multirow{2}{*}{$\begin{array}{c}\text { A } \\
(\text { deg })\end{array}$} & \multirow{2}{*}{$\begin{array}{c}\text { Arrival } \\
\text { time } \\
\left(\mathbf{T}_{\mathrm{a}}\right) \\
(\mathrm{ms})\end{array}$} & \multirow{2}{*}{$\begin{array}{c}\text { Load } \\
\text { duration } \\
\text { time } \\
\left(\mathbf{T}_{\mathrm{d}}\right) \\
(\mathrm{ms})\end{array}$} & \multirow{2}{*}{$\begin{array}{c}\text { Pr } \\
\text { (psi) }\end{array}$} & \multirow{2}{*}{$\begin{array}{l}\text { Load } \\
(\mathrm{KN})\end{array}$} \\
\hline Story & & & & & & \\
\hline 1 & 28.01 & 13.54 & 6.38 & 2.64 & 228 & 10997 \\
\hline 2 & 31.49 & 34.95 & 7.95 & 3.07 & 148 & 5354 \\
\hline 3 & 37.13 & 48.67 & 10.79 & 4.63 & 70 & 2532 \\
\hline 4 & 44.28 & 58.4 & 14.85 & 6.36 & 37 & 1338 \\
\hline 5 & 52.32 & 65.38 & 19.93 & 7.67 & 24 & 868 \\
\hline 6 & 70.2 & 70.2 & 25.77 & 9.15 & 16 & 579 \\
\hline
\end{tabular}


Blast load may is applied in SAP 2000 using time history function as shown in Figure 3.

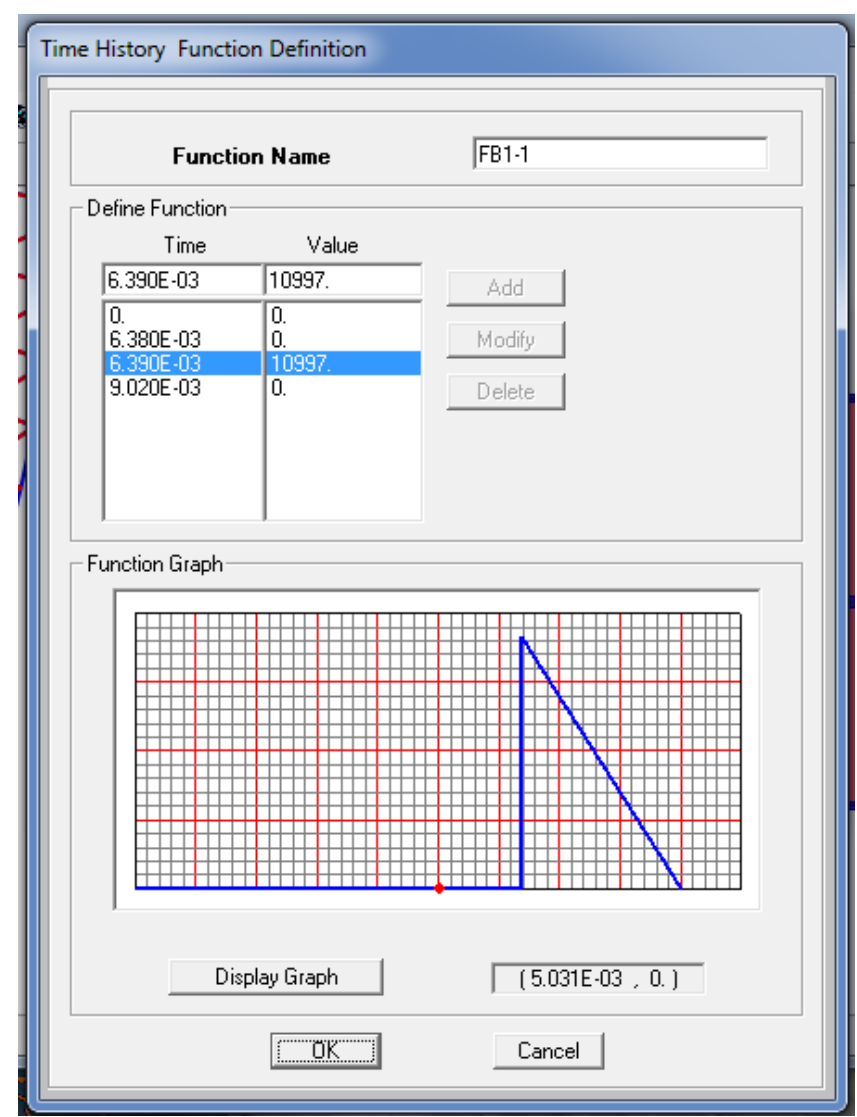

Fig 3. Time history function in SAP2000

\section{RESULTS AND DISCUSSIONS}

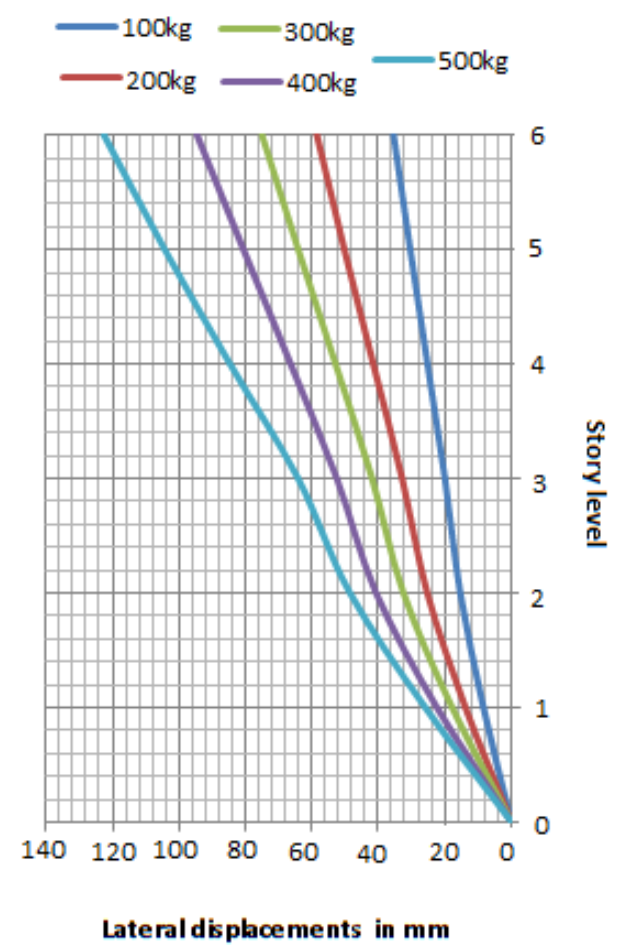

Fig 4. Lateral displacements for a 6 story building with different charge weights placed at $6 \mathrm{~m}$ stand-off distance
Blast load assessment is a difficult procedure as there are a number of factors affecting the performance of the building. Dynamic analysis is carried out to investigate the lateral stability of a structure.

Time history functions for lateral displacements and inter story drift to know the lateral stability of the structure.

In Figure 4, the maximum lateral displacements are $35.4 \mathrm{~mm}$, $58.6 \mathrm{~mm}, 75.1 \mathrm{~mm}, 94.7 \mathrm{~mm}, 122.72 \mathrm{~mm}$ for charge weight of $100 \mathrm{~kg}, 200 \mathrm{~kg}, 300 \mathrm{~kg}, 400 \mathrm{~kg}$ and $500 \mathrm{~kg}$ TNT respectively placed at $6 \mathrm{~m}$ standoff distance.

As per IS1893 the allowable maximum lateral displacement is $38 \mathrm{~mm}$ ( i.e H/500). So, the maximum lateral displacement is satisfying for only $100 \mathrm{~kg}$ TNT and other charge weights are not satisfying the IS code provisions

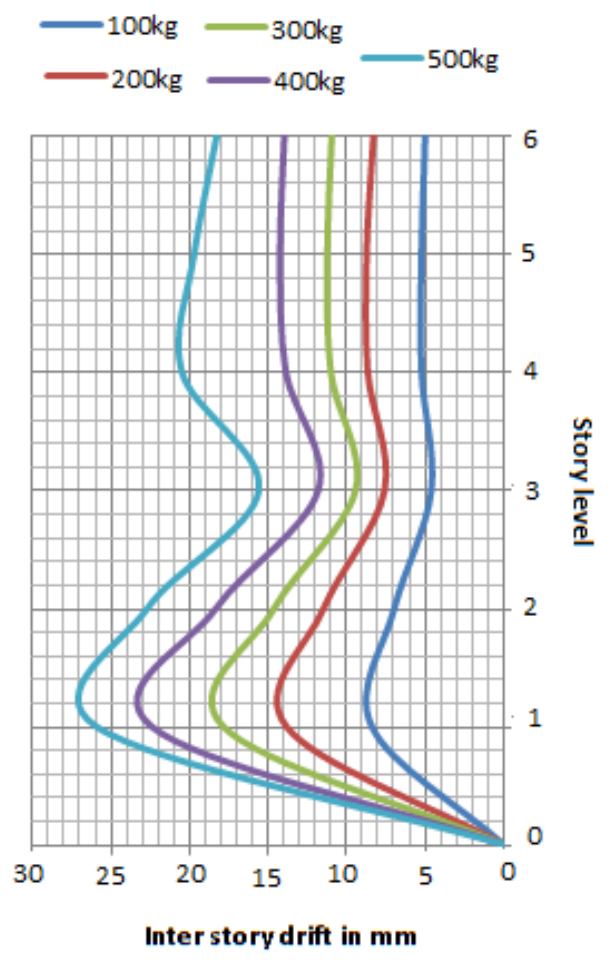

Fig 5. Inter story drift for a 6 story building with different charge weights placed at $6 \mathrm{~m}$ stand-off distance

In Figure 5, the maximum inter story drifts are $8.39 \mathrm{~mm}$, $13.84 \mathrm{~mm}, 17.87 \mathrm{~mm}, 22.43 \mathrm{~mm}$ and $25.95 \mathrm{~mm}$ for charge weight of $100 \mathrm{~kg}, 200 \mathrm{~kg}, 300 \mathrm{~kg}, 400 \mathrm{~kg}$ and $500 \mathrm{~kg}$ TNT respectively placed at $6 \mathrm{~m}$ standoff distance.

As per IS1893 the allowable maximum Inter story drift is $16 \mathrm{~mm}$ (i.e $0.004 \mathrm{xh}$ ). So, the maximum story drift are satisfying for charge of $100 \mathrm{~kg}$ and $200 \mathrm{~kg}$ TNT and other charge weights are not satisfying the IS code provisions.

Table II shows the variation of blast pressure, along the height of the structure for different charge weights at a standoff distance $6 \mathrm{~m}$. 
TABLE II. Variation of blast pressure, along the height of the structure for different charge weight at a standoff distance $6 \mathrm{~m}$

\begin{tabular}{|c|c|c|c|c|c|}
\hline \multirow{2}{*}{ Story } & \multicolumn{5}{|c|}{ Different charge weights of TNT } \\
\cline { 2 - 6 } & $\mathbf{1 0 0 k g}$ & $\mathbf{2 0 0 k g}$ & $\mathbf{3 0 0 k g}$ & $\mathbf{4 0 0 k g}$ & $\mathbf{5 0 0 k g}$ \\
\hline 1 & 303. & 593 & 853 & 1095 & 1323 \\
\hline 2 & 159 & 326 & 489 & 640 & 783 \\
\hline 3 & 64 & 120 & 183 & 248 & 315 \\
\hline 4 & 37 & 59 & 81 & 107 & 133 \\
\hline 5 & 24 & 36 & 46 & 56 & 67 \\
\hline 6 & 16 & 24 & 31 & 37 & 43 \\
\hline
\end{tabular}

Figure 6 shows the variation of pressure with different charge weights at $6 \mathrm{~m}$ stand-off distance.

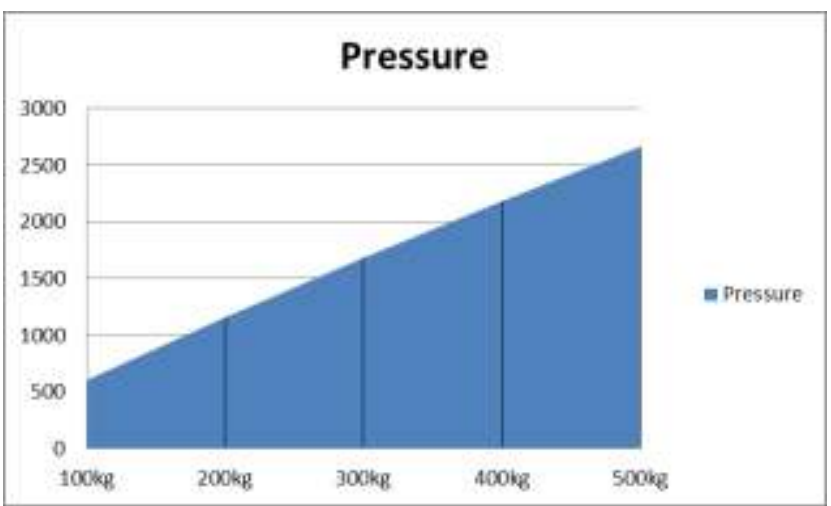

Fig 6. Variations of pressure for different charge weight

\section{CONCLUSIONS}

From the above results, the conclusions drawn are,

- The maximum lateral displacements are $35.4 \mathrm{~mm}$, $58.6 \mathrm{~mm}, 75.1 \mathrm{~mm}, 94.7 \mathrm{~mm}, 122.72 \mathrm{~mm}$ for charge weight of $100 \mathrm{~kg}, 200 \mathrm{~kg}, 300 \mathrm{~kg}, 400 \mathrm{~kg}$ and $500 \mathrm{~kg}$ TNT respectively placed at $6 \mathrm{~m}$ standoff distance. As per IS1893 the allowable maximum lateral displacement is $38 \mathrm{~mm}$ (i.e H/500). So, the maximum lateral displacements is satisfying for only $100 \mathrm{~kg}$ TNT and for other charge weights not satisfying the IS code provisions. (Figure 4)

- The maximum inter story drift are $8.39 \mathrm{~mm}, 13.84 \mathrm{~mm}$, $17.87 \mathrm{~mm}, 22.43 \mathrm{~mm}$ and $25.95 \mathrm{~mm}$ for charge weight of $100 \mathrm{~kg}, 200 \mathrm{~kg}, \quad 300 \mathrm{~kg}, 400 \mathrm{~kg}$ and $500 \mathrm{~kg}$ TNT respectively placed at $6 \mathrm{~m}$ standoff distance. As per IS1893 the allowable maximum Inter story drift is $16 \mathrm{~mm}$ (i.e $0.004 \mathrm{xh}$ ). So, the maximum story drift are satisfying for charge of $100 \mathrm{~kg}$ and $200 \mathrm{~kg}$ TNT and other charge weights are not satisfying the IS code provisions. (Figure 5 )

- Reflected positive pressure increases when the charge weight increases. (Figure 6)

\section{ACKNOWLEDGMENT}

The authors sincerely thank Dr. Vijayalakshmi Akella, Professor and Head, Department of Civil Engineering and
Dr. S.N. Sridhara, Principal, K S school of Engineering and Management, Bangalore for their encouragement and for providing facilities to carry out this research work as a part of M.Tech. project.

\section{REFERENCES}

[1] T. Ngo, P. Mendis, A. Gupta \& J. Ramsay " Blast Loading and Blast Effects on Structures - An Overview" EJSE Special Issue: Loading on Structures ,The University of Melbourne, Australia 2007.

[2] Hrvoje Draganić, Vladimir Sigmund. "Blast Loading On Structures" Technical Gazette 19, ISSN 1330-3651 2012

J. Clerk Maxwell, A Treatise on Electricity and Magnetism, 3rd ed., vol. 2. Oxford: Clarendon, 1892, pp.68-73.

[3] Wenbin Sun, Yang Jiang, Weizhong He "An Overview on the Blast Loading and Blast Effects on the RC Structures. Applied Mechanics and Materials Vols. 9496, pp 77-80 2011

[4] Lucia FIGULI, Vlasdimir KAVICKY, Kamil BOC, Dagmar VIDRIKVA, Stefan JANGL" ANALYSIS OF BLAST LOADED STRUCTURES" Science and Military,

[5] Zeynep Koccaz, Fatih Sutcu,Necdet Torunbalci "ARCHITECTURAL AND STRUCTURAL DESIGN FOR BLAST RESISTANT BUILDINGS" The 14th World Conference on Earthquake Engineering 2008, Beijing, China 2013

[6] Juraj Králik, Peter Rozsá "SAFETY AND RELIABILITY ANALYSIS OF THE HIGH RISE BUILDINGS CONSIDERING THE EXTERIOR EXPLOSION EFFECT "Journal of KONBiN 2,3 $(14,15) 2010$ ISSN 1895-8281

[7] Li Tian, Haixian Song "Tilt Response of Multi-storey Building of DifferentTypes Due to Progressive Collapse of the Adjacent Underground Structure under Internal Blast Loading" Applied Mechanics and Materials Vols. 226-228 (2012) pp 1023-1028

[8] Cătălin BACIU, Marin LUPOAE " Nonlinear Analysis For a Reinforced Concrete Frame Structure Under Extreme Loads " Mechatronics Department of MilitaryTechnical Academy, Bucharest, Romania 